\title{
A Psychometric Evaluation of the Cultural Receptivity in Fostering Scale
}

By: Tanya M. Coakley, John G. Orme

Coakley, T. M., \& Orme, J. G. (2006). A psychometric evaluation of the Cultural Receptivity in Fostering Scale. Research on Social Work Practice, 16(5), 520-533. doi:

$10.1177 / 1049731506287080$

Made available courtesy of Sage Publications: $\underline{\text { http://dx.doi.org/10.1177/1049731506287080 }}$

***@) Sage Publications. Reprinted with permission. No further reproduction is authorized without written permission from Sage Publications. This version of the document is not the version of record. Figures and/or pictures may be missing from this format of the document. $* * *$

\begin{abstract}
:
Objective: The psychometric properties of a new measure of foster parents' openness toward participating in activities that promote children's cultural development are evaluated. The measure is titled the Cultural Receptivity in Fostering Scale (CRFS). Method: Data from 304 foster mothers who completed the CRFS and a battery of measures on psychosocial functioning are analyzed. Results: The CRFS demonstrates excellent internal consistency reliability and, to some extent, construct validity. Conclusions: The internal consistency reliability and, to some extent, validity of the CRFS is supported by these findings. The measure has potential use in facilitating socially appropriate and successful transcultural placements.
\end{abstract}

Keywords: cultural competence | foster care | foster parent | transracial | assessment

\section{Article:}

In 2003, three fourths of the 523,085 children in foster care lived with foster families (U.S. Department of Health and Human Services [DHHS], 2005). Even with the rise in the use of kinship homes, agencies placed approximately two thirds of children in nonkinship foster families (DHHS, 2005).

Currently, there is a shortage of foster parents of minority cultures and an overrepresentation of children of minority cultures in the foster care system. This disparity has resulted in transcultural placements. Children who are raised by transcultural foster parents are potentially at risk for various developmental and psychosocial problems due to their cultural needs not being met (Curtis, 1996; Deberry, Scarr, \& Weinberg, 1996; McRoy, 1994; Thoburn, Norford, \& Rashid, 2000; Vonk, 2001; Zuniga, 1991).

\section{CULTURAL RECEPTIVITY AND TRANSCULTURAL FOSTER CARE}


In 1998, about $15 \%$ of adoptions of foster children were transracial or transcultural (U.S. Department of Health and Human Services [DHHS], 2000). Approximately 45\% of foster parents report caring for children from more than one racial background (Rhodes, Cox, Coakley, \& Orme, under review). It is thus important that foster parents be willing and able to promote the development of foster children's cultural and racial identities (Massatti, Vonk, \& Gregoire, 2004; McRoy, 1994; Vonk, 2001). This requires that foster parents be open and receptive to the role that culture and race play in children's development.

Cultural receptivity, a new construct developed by the authors, measures foster parents' openness toward participating in activities that promote children's cultural development. Specifically, it involves one's openness to support foster children's relationships with adults and children who share their cultures, find resources where the children can go to get their cultural needs met, learn about parenting strategies of the children's cultures, and learn from others who have successfully parented children of different cultures.

Assessing the cultural receptivity of prospective foster parents is important for a number of reasons. An understanding of foster parent applicants' cultural receptivity in fostering allows social workers to tailor their recruitment, training and support, and retention efforts accordingly, in order to increase and enhance the pool of qualified and committed transcultural foster parents. In addition, there are important transcultural parenting outcomes that warrant examination, such as how foster parents' cultural receptivity is related to willingness to foster, cultural competence, and ability to foster. These variables, as well as other antecedent and outcome variables, are addressed in this study in order to validate interpretation of test scores for the Cultural Receptivity in Fostering Scale (CRFS).

A great deal of research has been conducted to assess the relationship between the effectiveness of social services and culture, and there also is some degree of research specific to outcomes for transcultural child placement. A predominance of the research on transcultural parenting successes, however, is based primarily on psychosocial outcomes and on aspects of foster children's social adjustments, such as academic achievements and relationship with parents and peers, without consideration of the importance of culture on children's development or the social appropriateness of care. These types of studies found that transcultural placements had no adverse effects on children and that transracial adoptees faired just as well as same-race adoptees (McRoy \& Zurcher, 1983; Sharma, McGue, \& Benson, 1996; Shireman \& Johnson, 1986; Silverman, 1993; Simon \& Alstein, 1996; Vroegh, 1997).

According to several studies, approximately $75 \%$ to $90 \%$ of African American children who have been placed transracially have had successful adjustment outcomes (Feigelman \& Silverman, 1983; Grow \& Shapiro, 1974; McRoy \& Zurcher, 1983; Silverman, 1993; Vroegh, 1997). However, due to methodological shortcomings in the research, particularly limitations related to sampling and measurement issues, there are still important gaps in knowledge (Coakley, 2004). 
The research is insufficient to determine definitively the outcomes of transcultural placements. This is partly due to researchers' failure to measure appropriate variables concerning children's cultures and the failure to consistently measure these cultural variables using valid and reliable measures. First, without considering these important variables related to children's cultures in addition to their psychosocial development, it is impossible to know how they will affect outcomes such as cultural identity and development. Second, these cultural variables must be measured using measures with demonstrated reliability and validity. Reliable and valid measures are useful in obtaining quantitative data and will add to the scarcity of empirical research on transcultural fostering.

Receptivity to children's cultures seems to be a useful concept for foster care, but the literature includes no conceptual or empirical references to the issue. Also, to our knowledge, no measure of cultural receptivity has existed heretofore with which to conduct such research or to assess prospective foster parents. Therefore, the purpose of this study is to test the psychometric properties of the CRFS, a new standardized measure designed to assess foster parents' level of cultural receptivity. Specifically, the factorial structure of this measure will be explored, and the reliability of the factors identified will be examined. Finally, hypotheses will be tested to examine the construct validity of the CRFS.

\section{METHOD}

\section{Sample and Design}

This study is part of a larger project designed to examine the psychometric properties of new and existing standardized measures for assessing a broad range of characteristics of foster parents thought related to the quality of family foster care. The University of Tennessee Institutional Review Board approved all study procedures for the requirements of human participants.

Data were collected from October 2002 through September 2003. Using a cross-sectional design, a total of 304 approved, certified, or licensed nonkinship and kinship foster mothers were recruited nationally to participate voluntarily in the study. Foster mothers were sampled because they are usually the ones who initiate fostering, play the primary role in fostering, and head most single-parent foster families. Foster mothers' demographic characteristics are shown in Table 1.

Foster mothers were recruited through state and local foster parent associations. The list of these associations was obtained from the web site of the National Foster Parent Association (NFPA) (www.nfpainc.org), which endorsed this study. Recruitment information packets that included information about the study and tools for distributing information to foster parents were sent to state and local foster parent associations by mail and e-mail. (Buehler, Orme, Cuddeback, Le Prohn, \& Cox, 2003; Orme, Cuddeback, Buehler, Cox, \& Le Prohn, 2003). Each contained multiple scales, subscales, and other questions. Completion order of the two questionnaires was counterbalanced to reduce the possibility of fatigue, practice, carryover, or order effects (Shadish, Cook, \& Campbell, 2002). Specifically, respondents were asked to complete the 
CHAP-SR first and the CFAI-A second for oddnumbered questionnaires, and vice versa for evennumbered questionnaires.

Table 1. Foster Mothers’ Demographic Characteristics

\begin{tabular}{|c|c|}
\hline Characteristic & $\%$ \\
\hline \multicolumn{2}{|l|}{ Marital status ( $\mathrm{n}=303$ ) } \\
\hline Married, no stepchildren & 57.1 \\
\hline Married, stepchildren & 17.5 \\
\hline Domestic partnership & 4.0 \\
\hline \multicolumn{2}{|l|}{ Single, never married 6.3} \\
\hline Widowed & 3.0 \\
\hline Divorced or separated & 12.2 \\
\hline \multicolumn{2}{|l|}{ Race $(\mathrm{n}=304)$} \\
\hline European American & 87.2 \\
\hline African American & 10.5 \\
\hline Hispanic & 3.0 \\
\hline American Indian & 2.0 \\
\hline \multicolumn{2}{|l|}{ Highest degree $(n=304)$} \\
\hline$<$ high school & 2.2 \\
\hline High school/general education degree (GED) & 21.7 \\
\hline College, no degree & 29.9 \\
\hline 2-year degree & 16.8 \\
\hline Bachelor's degree & 18.8 \\
\hline Advanced degree & 10.5 \\
\hline \multicolumn{2}{|l|}{ Employment status $(\mathrm{n}=304)$} \\
\hline Full-time & 32.6 \\
\hline Part-time & 17.1 \\
\hline Unemployed, looking for work & 1.0 \\
\hline Homemaker, not employed outside home & 34.9 \\
\hline Disabled or retired, not employed outside home & 7.2 \\
\hline Other & 7.2 \\
\hline Yearly family income $(\mathrm{n}=302)<\$ 10,000$ & 1.3 \\
\hline$\$ 10,000-\$ 19,999$ & 6.3 \\
\hline$\$ 20,000-\$ 29,999$ & 10.6 \\
\hline$\$ 30,000-\$ 39,999$ & 20.2 \\
\hline$\$ 40,000-\$ 49,999$ & 11.5 \\
\hline$\$ 50,000-\$ 59,999$ & 15.2 \\
\hline$\$ 60,000-\$ 69,999$ & 11.3 \\
\hline$\$ 70,000-\$ 79,999$ & 7.0 \\
\hline$\$ 80,000-\$ 89,999$ & 6.3 \\
\hline$\$ 90,000-\$ 99,999$ & 3.9 \\
\hline$\geq \$ 100,000$ & 6.3 \\
\hline
\end{tabular}

NOTE: Race percentages do not add up to $100 \%$ because foster mothers were asked to select all that applied. 


\section{CRFS}

The CRFS is a new 25-item scale designed to measure respondents' level of openness toward activities that support children's cultural growth and development. It has a potential range of values from 0 through 100. Each item is rated on a 5-point Likert-type scale: none (1), little (2), some (3), a lot (4), and whatever it takes (5).

Development of the CRFS content was accomplished through a national review of foster care professional norms, foster care standards, and training manuals (e.g., Child Welfare League of America, 2000; Illinois Department of Children and Family Services, 1993; Pasztor \& Child Welfare Institute \& Center for Foster and Residential Care, 1990; Rhodes, Coakley, \& Orme, 2002). There also was an extensive review of literature on general foster family research and practice, cultural competence, and racial identity development. The Multiethnic Placement Act [MEPA] (1994) and the Interethnic Adoption Provision [IEAP] (1996), laws that govern transcultural placements, also were examined.

The literature suggested that there are four overall domains of cultural receptivity: (a) understanding of different cultures; (b) willingness to become aware of children's need for cultural identity; (c) effort to learn about availability of resources to support children's identities; and (d) appreciation of other cultures. Based on those domains, a pool of 39 potential items was established from which a new universe of 25 items was ultimately generated to reflect the cultural receptivity construct. Next, items were added to and others deleted from the CRFS pool on the basis of which items best represented respective cultural receptivity content domains.

The CRFS was reviewed by several researchers, child welfare administrators, and policy makers of various demographics. The reviews occurred at several different phases of the scale development in order to establish validity evidence that supports the content of the scale (American Educational Research Association, American Psychological Association, \& National Council on Measurement in Education standards [AERA, APA, NCME], 1999).

Once the content was established for the CRFS, 10 foster mothers and 10 public and private foster care workers from various cultural backgrounds evaluated the CRFS using an evaluation form. At this stage of review, feedback was provided regarding the clarity, relevancy, and representation of items intended to measure the construct, cultural receptivity (AERA, APA, NCME, 1999). This process assisted in supporting content validity and ensuring the usefulness of the measure for foster mothers. The final version of the CRFS can be found in the appendix.

\section{CHAP-SR Questionnaire}

The CHAP-SR questionnaire contains a variety of scales and questions, and all of these are described in detail in Rhodes, Orme, et al. (2003) and Orme, Cox, et al. (2003). The CHAP-SR contains self-report scales developed as part of the larger project to measure important and relatively unique aspects of foster parenting, and the CRFS is one of these scales. The CHAP-SR 
also contains self-report scales designed to measure aspects of parenting and individual and family functioning not necessarily unique to foster parenting.

Selected scales from the CHAP-SR were conceptualized as correlates of cultural receptivity and were used to examine the construct validity of the CRFS. These hypothesized relationships are based on our preliminary conceptualization of cultural receptivity and its hypothesized antecedents and outcomes, and the related literature reviewed above. However, given that the CRFS is a new measure of a new concept, these hypothesized relationships should be viewed as tentative.

Personal Dedication to Fostering Scale (PDFS). The PDFS is a new 18-item scale, with a potential range of values from 0 through 100 . Higher scores indicate greater professional commitment, moral, and/or ethical consciousness, receptivity, and responsivity to foster children.

Available Time Scale (ATS). The ATS is a new 20-item scale, with a potential range of values from 0 through 100 . Higher scores indicate more anticipated time available to complete tasks that are typical of foster parent responsibilities.

Foster Parent Role Performance Scale (FPRPS). The FPRPS is a 40-item scale that has two subscales, each with a potential range of values from 0 through 100 (Le Prohn, 1993, 1994; Pecora, Le Prohn, \& Nasuti, 1999; Rhodes, Orme, \& McSurdy, 2003). Higher subscale scores indicate a greater degree of perceived responsibility for (a) parenting (23 items) and (b) working with the foster care agency (17 items).

Parental Acceptance Scale (PAS). The PAS is a 10-item scale, with a potential range of values from 1 through 3 (Schaefer, 1965; Schludermann \& Schludermann, 1970). Higher scores indicate greater parental acceptance of children.

Barnett Liking of Children Scale (BLOCS). The BLOCS is a 14-item scale, with a potential range of values from 14 through 98 (Barnett \& Sinisi, 2000). Higher scores indicate a greater tendency to like children.

Help with Fostering Inventory (HFI). The HFI is a new 28-item scale with three subscales, and each subscale has a potential range of values from 0 through 100 (Orme, Cherry, \& Rhodes, in press). Higher subscale scores indicate more anticipated help with fostering from (a) worship groups (4 items), (b) professionals (11 items), and (c) extended kin (4 items).

Cultural Competence Scale (CCS). The CCS is a 27-item scale, with a potential range of values from 27 through 135 (Mitchell, 1999). Higher scores indicate greater cultural competence.

Receptivity to Birth Family Connections Scale (RBFCS). The RBFCS is a new 14-item scale, with a potential range of values from 0 through 100 . Higher scores indicate greater professional commitment, moral and/or ethical consciousness, receptivity, and responsivity to birth parents. 
Willingness to Foster Scale (WFS). The WFS is a new 70-item scale with five subscales, and each subscale has a potential range of values from 0 through 100 . Higher subscale scores indicate a greater willingness to foster (a) children with emotional and behavioral problems (40 items); (b) children with special needs (19 items); (d) children of different races, religions, cultures, or sexual orientation (DRRCS) (4 items); (d) children age 5 and under (3 items), and (e) children age 6 and over (4 items) (the latter two subscales were not used in the present study).

\section{Casey Foster Applicant Inventory-Applicant Questionnaire}

The CFAI-A questionnaire contains a variety of scales and questions, and all of these are described in detail in Buehler et al. (2003) and Orme, Cuddeback, et al. (2003). Selected scales and questions were conceptualized as correlates of cultural receptivity and were used to examine the validity of the CRFS. The CFAI-A questionnaire also contains questions concerning demographic and background characteristics used to describe the sample, and these are described next.

The CFAI-A is a new 74-item scale with six subscales, and each subscale has a potential range of values from 0 through 100 . Higher subscale scores indicate greater potential to (a) promote foster child development (30 items), (b) foster challenging children (13 items), (c) manage challenging relationships with foster care workers and agencies (9 items), (d) co-parent foster children (10 items, applicable only in two-parent foster families), (e) integrate foster children into a foster family with birth or adopted children (6 items, applicable only to foster families with birth or adopted children), and (f) provide care to children of a relative (6 items, applicable only to foster families who provide kinship care).

Agency information regarding racially or culturally different children. Foster mothers were asked to report the extent of information they had received about working with a racially or culturally different child. This item is rated on a 3-point Likert-type scale: (0) no information, (1) some information, but not enough, and (2) enough information.

Demographic characteristics. Foster mothers indicated their age, current employment status, highest degree or level of school completed, marital status, race and/or ethnic background, religious background, and total family income in the past year, from all sources before taxes.

They provided data about the total number of children living in the home, the number of birth and adopted children not living in the home, and the age of each of these children. Finally, foster mothers reported whether they were licensed to provide the following types of care, checking all that applied: foster family home, emergency care home, specialized foster family home, relative foster home, group home, or other (specify).

Availability and utilization of foster family services. Foster mothers were asked five questions concerning availability to foster, including the number of years they had fostered and the number 
of foster children their homes are licensed to accept at one time. In addition, they indicated if they intended to continue fostering over the next 6 months, the next year, and the next 3 years.

Foster mothers responded to four questions concerning the extent to which they in fact provided care to foster children. They were asked to report the number of foster children cared for since they began fostering, the number of foster children adopted, the number of foster children removed at their request, and the number of foster children currently in their homes.

\section{RESULTS}

In this section, we first describe the demographic and background characteristics of participating foster mothers. Second, we provide internal consistency reliability estimates for the scales utilized to measure the antecedent and outcome variables used to test validity hypotheses, and we include descriptive statistics for all of these variables. Third, we examine the factorial structure of the CRFS. Fourth, we examine the reliability of the CRFS. Fifth, we provide descriptive statistics for the CRFS. Finally, we examine empirical evidence concerning the validity of the CRFS.

\section{Demographic and Background Characteristics}

The 304 foster mothers in this sample lived in 35 different states (see Table 2), and the sample size in the analyses below is 304 unless noted otherwise. Most foster mothers were married, European American, and had a high school education or some college (see Table 1). About one third worked full-time outside of the home and about one third were homemakers, not employed outside the home. The mean age was $44.31(S D=9.95, n=299)$. The median yearly family income was approximately $\$ 50,000$. Finally, on average there were three children in the home $(M=3.34, S D=1.95)$, two of whom were birth or adopted children $(M=1.60, S D=1.54, n=$ $299)$, and one who was younger than 6 years old $(M=1.03, S D=1.20, n=293)$.

The vast majority of homes in which these foster mothers lived were licensed as foster family homes. Of the 24 not licensed as foster family homes, most were licensed as specialized foster family homes $(79.2 \%, n=19)$, and the remaining five homes were licensed either as emergency care homes $(16.7 \%, n=4)$, relative foster homes $(4.2 \%, n=1)$, or other $(25.0 \%, n=6)$. Although few homes were licensed as relative homes, 65 (21.4\%) provided kinship care.

\section{Antecedents and Outcomes}

Coefficient alpha ranged from .80 to .96 for most of the scales. For three of the scales coefficient alpha ranged from .73 to .78. Coefficient alpha for the Willingness to Foster DRRCS scale was .66 (see Table 3).

The remaining outcome variables were those used to measure the availability and utilization of foster family placements. Most mothers planned to continue fostering for 6 months (95.4\%), 1 year (93.7\%), and 3 years (89.8\%). On average, mothers had fostered about 5 years and were 
licensed to foster 3 children (see Table 4). Typically these mothers had fostered 11 or more children, had only requested that 1 be removed, had adopted 1 foster child, and had 1 or 2 foster children in their home at the time of participation in this study. However, 19\% had no foster children in their homes and $74 \%$ were below licensed capacity.

\section{CRFS Factorial Structure}

An exploratory factor analysis (EFA) of the CRFS was conducted to explore whether one or more dimensions underlie the item scores. EFA was used because the CRFS is a new measure of a new concept and there is not enough information to specify the underlying factor structure (Fabrigar,Wegener, MacCallum, \& Strahan, 1999; Loehlin, 1998).

Table 2. Participants by States

\begin{tabular}{|l|l|l|}
\hline State & Frequency & $\%$ \\
\hline AK & 3 & 1.0 \\
\hline AR & 17 & 5.6 \\
\hline AZ & 3 & 1.0 \\
\hline CA & 12 & 3.9 \\
\hline CO & 3 & 1.0 \\
\hline CT & 12 & 3.9 \\
\hline FL & 3 & 1.0 \\
\hline GA & 3 & 1.0 \\
\hline IA & 15 & 4.9 \\
\hline ID & 4 & 1.3 \\
\hline IL & 1 & .3 \\
\hline IN & 31 & 10.2 \\
\hline KS & 11 & 3.6 \\
\hline KY & 15 & 4.9 \\
\hline LA & 5 & 1.6 \\
\hline MA & 5 & 1.6 \\
\hline MI & 2 & .7 \\
\hline MN & 12 & 3.9 \\
\hline MO & 1 & .3 \\
\hline MT & 3 & 1.0 \\
\hline NC & 12 & 3.9 \\
\hline NH & 1 & .3 \\
\hline NV & 25 & 8.2 \\
\hline NY & 3 & 1.0 \\
\hline OH & 4 & 1.3 \\
\hline OK & 2 & .7 \\
\hline PA & 4 & 1.3 \\
\hline RI & 1 & .3 \\
\hline TN & 22 & 7.2 \\
\hline TX & 6 & 2.0 \\
\hline & & \\
\hline
\end{tabular}




\begin{tabular}{|l|l|l|}
\hline VA & 5 & 1.6 \\
\hline VT & 4 & 1.3 \\
\hline WA & 46 & 15.1 \\
\hline WI & 7 & 2.3 \\
\hline WY & 1 & .3 \\
\hline Total & 304 & 100.0 \\
\hline
\end{tabular}

Unweighted least squares was used to extract factors because it leads to a consistent estimation of model parameters without the assumption that the observed variables have a particular distribution. Most of the item distributions were skewed negatively, although some were relatively normal (see Table 5).

Bartlett's test of sphericity $[\chi 2(190, n=303)=6,095.15, p<.001]$ and the Kaiser-Meyer-Olkin measure of sampling adequacy (.96) strongly supported the suitability of the CRFS items for factor analysis. The scree test clearly indicated a one-factor solution. All of the factor loadings in the structure matrix were above .61 (see Table 5).

\section{CRFS Internal Consistency Reliability}

All of the corrected-item total correlations were .60 or greater (see Table 5), and Cronbach’s alpha was .97.

\section{CRFS Scoring and Descriptive Statistics}

A total score was computed for the CRFS using the following formula:

$$
S=\frac{(M-1)(100)}{K-1}
$$

where $\mathrm{S}=$ the scale score, $\mathrm{M}=$ the mean item score, and $\mathrm{K}=$ the largest possible value for an item response. This formula results in a potential range of values from 0 through 100 , and higher scores indicate greater cultural receptivity, as stated previously.

The distribution of CRFS total scores indicated relatively high cultural receptivity, negative skew (skew =-.95, $S E=.14$ ), and positive kurtosis (kurtosis $=2.03, S E=.28$ ). These results indicate that in comparison to a normal distribution, the distribution of the CRFS total scores is negatively skewed with a long left tail. Also, it is positively kurtotic, therefore, the scores tend to cluster more so than they would in a normal distribution.

The mean CRFS score for foster mothers was $80.42(S D=15.25)$ and the median was 82.00. The 25th percentile was 72.00 and the 75th percentile was 93.00 .

\section{CRFS Validity}


Validity hypotheses. Three sets of hypotheses were formulated to investigate the relationship between cultural receptivity and a broad range of external variables, and nondirectional hypotheses with $\alpha=.05$ were tested for all hypotheses, because results in either direction would be important. First, the extent, if any, to which demographic characteristics are related to cultural receptivity was examined. We hypothesized that there is a small relationship between cultural receptivity and foster mothers' education level, race and/or ethnicity, marital status, and yearly family income. If demographic characteristics account for an appreciable amount of variance in CRFS scores, it would raise questions about the discriminant validity of the CRFS.

Second, antecedents hypothesized to be related positively to cultural receptivity were examined. These included indicators of the extent to which foster mothers like and accept children, are committed to the foster parent role, have time to foster, received information about fostering racially or culturally different children, and anticipate help with fostering from professionals.

TABLE 3. Descriptive Statistics and Reliability for Scales

\begin{tabular}{|c|c|c|c|c|c|}
\hline Scale & $\mathrm{M}$ & SD & Mdn & $\alpha$ & $\mathrm{n}$ \\
\hline \multicolumn{6}{|l|}{ Antecedents } \\
\hline Personal dedication to fostering & 76.29 & 9.22 & 75.93 & .80 & 304 \\
\hline Available time scale & 77.28 & 12.73 & 77.50 & .87 & 304 \\
\hline Perceived responsibility to parent & 77.21 & 11.24 & 77.17 & .88 & 304 \\
\hline Perceived responsibility to work with foster care agency & 34.68 & 15.34 & 32.35 & .87 & 304 \\
\hline Parental Acceptance Scale & 2.82 & 0.22 & 2.90 & .75 & 304 \\
\hline Tendency to like children & 86.91 & 8.31 & 88.00 & .81 & 303 \\
\hline Help with fostering-professionals & 67.85 & 21.02 & 72.73 & .81 & 304 \\
\hline $\begin{array}{l}\text { Agency information regarding racially or culturally different } \\
\text { children }\end{array}$ & 2.24 & 0.69 & 2.00 & 304 & \\
\hline \multicolumn{6}{|l|}{ Outcomes } \\
\hline Cultural competence & 96.15 & 15.19 & 97.00 & .93 & 304 \\
\hline Potential to promote foster child development & 50.00 & 9.99 & 48.91 & .92 & 304 \\
\hline Potential to foster challenging children & 49.99 & 9.99 & 51.05 & .85 & 304 \\
\hline Potential to manage worker and agency challenges & 50.00 & 9.99 & 51.22 & .73 & 304 \\
\hline Receptivity to work with birth families & 70.91 & 9.90 & 69.04 & .78 & 304 \\
\hline Willingness to foster (emotional and behavior problems) & 57.33 & 18.97 & 57.50 & .96 & 297 \\
\hline Willingness to foster (special needs) & 65.98 & 18.75 & 64.91 & .90 & 290 \\
\hline $\begin{array}{l}\text { Willingness to foster (different race, religion, culture, or } \\
\text { sexual orientation) }\end{array}$ & 76.14 & 20.20 & 75.00 & .66 & 293 \\
\hline
\end{tabular}

NOTE: Alpha not applicable for scale item-Agency Information Regarding Racially or Culturally Different Children.

TABLE 4. Foster Family Availability and Utilization

\begin{tabular}{|l|l|l|l|l|}
\hline Variable & $\mathrm{M}$ & $\mathrm{SD}$ & $\mathrm{Mdn}$ & $\mathrm{n}$ \\
\hline Availability & \multicolumn{5}{|l|}{} \\
\hline Years fostered & 7.26 & 7.21 & 5.00 & 304 \\
\hline
\end{tabular}




\begin{tabular}{|l|l|l|l|l|}
\hline Licensed capacity & 3.41 & 1.69 & 3.00 & 303 \\
\hline \multicolumn{5}{|l|}{ Utilization } \\
\hline Children fostered & 32.93 & 67.56 & 11.00 & 304 \\
\hline Children removed & 2.29 & 4.17 & 1.00 & 295 \\
\hline Children adopted & 1.00 & 1.51 & 0.00 & 296 \\
\hline Children in home & 1.79 & 1.54 & 2.00 & 304 \\
\hline
\end{tabular}

TABLE 5: Cultural Receptivity in Fostering Scale Item Statistics and Exploratory Factor Analysis ( $(\mathbf{n}=304)$

\begin{tabular}{|l|l|l|l|l|}
\hline \multicolumn{7}{|l|}{ Item Statistics } \\
\hline Item & M & SD & Corrected Item-Total Correlation & Factor Loading \\
\hline 1 & 4.18 & .86 & .67 & .65 \\
\hline 2 & 4.59 & .70 & .60 & .62 \\
\hline 3 & 4.46 & .73 & .63 & .64 \\
\hline 4 & 4.23 & .80 & .74 & .75 \\
\hline 5 & 4.30 & .83 & .73 & .74 \\
\hline 6 & 4.40 & .79 & .69 & .70 \\
\hline 7 & 4.26 & .82 & .71 & .72 \\
\hline 8 & 4.56 & .69 & .71 & .73 \\
\hline 9 & 4.24 & .80 & .69 & .70 \\
\hline 10 & 4.01 & .92 & .69 & .69 \\
\hline 11 & 4.56 & .69 & .70 & .73 \\
\hline 12 & 3.95 & .84 & .69 & .69 \\
\hline 13 & 4.37 & .80 & .69 & .69 \\
\hline 14 & 4.29 & .78 & .80 & .80 \\
\hline 15 & 4.05 & .85 & .75 & .76 \\
\hline 16 & 3.91 & .86 & .73 & .73 \\
\hline 17 & 4.08 & .89 & .67 & .69 \\
\hline 18 & 4.17 & .82 & .84 & .86 \\
\hline 19 & 4.26 & .79 & .82 & .83 \\
\hline 20 & 4.02 & .84 & .83 & .85 \\
\hline 21 & 4.21 & .81 & .77 & .78 \\
\hline 22 & 4.08 & .83 & .76 & .78 \\
\hline 23 & 4.28 & .81 & .78 & .79 \\
\hline 24 & 4.08 & .84 & .79 & .81 \\
\hline 25 & 4.94 & .90 & .73 & .74 \\
\hline Eigenvalues & 13.48 & & \\
\hline$\%$ variance & 53.91 & & \\
\hline NO & & & & \\
\hline
\end{tabular}

NOTE: Data were missing for one participant for Item 16.

Finally, we hypothesized that cultural receptivity would be related positively to indicators of the availability and utilization of foster family placements and a number of other outcomes including willingness to foster different types of children, potential to provide family foster care, and 
receptivity to working with birth families. If CRFS scores are related to these antecedents and outcomes as hypothesized, it would provide support for the convergent validity of the CRFS.

Demographic characteristics. Linear regression was used to examine the effect of demographic characteristics on CRFS scores (Cohen, Cohen, West, \& Aiken, 2003). CRFS scores were regressed simultaneously on highest degree or level of education completed, race and/or ethnic background (European American [0] or African American and/or other [1]), marital status (not married or partnered [0] or married and/or otherwise partnered [1]), and total family income in the past year.

Overall, there was not a statistically significant relationship between demographic characteristics and CRFS scores (see Table 6). However, mothers who were married or otherwise partnered had lower CRFS scores, as did mothers with more education. Though the amount of variance in the CRFS scores accounted for by marital status $\left(r^{2}=.8 \%\right)$ and education level $\left(r^{2}=.6 \%\right)$ were very small, support for this hypothesis provides evidence of the discriminant validity of the CRFS.

TABLE 6. Cultural Receptivity in Fostering Scale Regressed on Demographic Characteristics (n $=301)$

\begin{tabular}{|l|l|l|l|l|l|}
\hline Demographic & $\beta$ & $\mathrm{B}$ & $\mathrm{SE}$ & $\mathrm{B}$ & $\mathrm{r}$ \\
\hline Education & $-.15^{*}$ & -1.44 & 0.63 & -.08 & \\
\hline European American & .04 & 1.68 & 2.67 & .02 & \\
\hline Married or partnered & $-.16^{*}$ & -6.03 & 2.42 & -.09 & \\
\hline Income & .13 & 0.19 & 0.10 & .03 & \\
\hline
\end{tabular}

TABLE 7. Bivariate Correlations Between Cultural Receptivity in Fostering Scale scores and Hypothesized Antecedents and Outcomes

\begin{tabular}{|c|c|c|}
\hline & $r$ & $\mathrm{n}$ \\
\hline \multicolumn{3}{|l|}{ Antecedents } \\
\hline Personal Dedication to Fostering Scale (PDFS) & $.38 * *$ & 304 \\
\hline Available Time Scale (ATS) & $.42 * *$ & 304 \\
\hline Foster Parent Role Performance Scale-Parenting (FPRPS-P) & $.32 * *$ & 304 \\
\hline Foster Parent Role Performance Scale-Agency (FPRPS-A) & $.26 * *$ & 304 \\
\hline Parental Acceptance Scale (PAS) & $.29 * *$ & 304 \\
\hline Barnett Liking of Children Scale (BLOCS) & $.23 * *$ & 303 \\
\hline Help with Fostering Inventory-Professionals(HFI-P) & $.15^{* *}$ & 304 \\
\hline Agency information regarding racially or culturally different children & $.12 *$ & 304 \\
\hline \multicolumn{3}{|l|}{ Outcomes } \\
\hline Cultural Competence Scale (CCS) & $.35 * *$ & 304 \\
\hline CFAI-A: Promote Foster Child Development (CFAI-A/FCD) & $.39 * *$ & 304 \\
\hline CFAI-A: Foster Challenging Children (CFAI-A/CC) & $.36 * *$ & 304 \\
\hline CFAI-A: Manage Worker/Agency Challenges (CFAI-A/WAC) & .10 & 304 \\
\hline Receptivity to Working with Birth Families Scale (RWBFS) & $.32 * *$ & 304 \\
\hline
\end{tabular}




\begin{tabular}{|l|l|l|}
\hline WFS: Behavioral or Emotional Problems (WFS-BEP) & $.25^{* *}$ & 297 \\
\hline WFS: Special Needs (WFS-SN) & $.23^{* *}$ & 290 \\
\hline WFS: DRRCS (WFS-DRRCS) & $.27^{* *}$ & 293 \\
\hline
\end{tabular}

NOTE: CFAI-A = Casey Foster Applicant Inventory-Applicant; WFS = Willingness to Foster Scale. ${ }^{*} \mathrm{p}<.05 .{ }^{* *} \mathrm{p}<.01$.

TABLE 8. Cultural Receptivity in Fostering Scale Regressed on Hypothesized Antecedents ( $\mathrm{n}=$ 303)

\begin{tabular}{|l|l|l|l|}
\hline Antecedents & $\beta$ & $\mathrm{B}$ & $\mathrm{SE}$ B \\
\hline Personal Dedication to Fostering Scale (PDFS) & $.19^{* *}$ & 0.32 & 0.10 \\
\hline Available Time Scale (ATS) & $.25^{* *}$ & 0.30 & 0.08 \\
\hline Foster Parent Role Performance Scale-Parenting (FPRPS-P) & .09 & 0.13 & 0.08 \\
\hline Foster Parent Role Performance Scale-Agency (FPRPS-A) & .04 & 0.04 & 0.06 \\
\hline Parental Acceptance Scale (PAS) & $.12^{* *}$ & 8.60 & 3.75 \\
\hline Barnett Liking of Children Scale (BLOCS) & .04 & 0.08 & 0.10 \\
\hline Help with Fostering Inventory- Professionals (HFI-P) & -.01 & -0.01 & 0.04 \\
\hline Agency information regarding racially or culturally different children & .05 & 1.14 & 0.10 \\
\hline
\end{tabular}

NOTE: CFAI-A = Casey Foster Applicant Inventory-Applicant; WFS = Willingness to Foster Scale. $\mathrm{R} 2=.27, \mathrm{~F}(8,294)=13.70, \mathrm{p}<.001 .{ }^{* *} \mathrm{p}<.01$.

Antecedents. Bivariate correlations were used to examine the effect of hypothesized antecedents on CRFS scores (see Table 7). All of these correlations were in the hypothesized direction and were statistically significant. Most ranged from .23 to .38 .

Linear regression was used to examine the overall and independent effects of hypothesized antecedents on CRFS scores (see Table 8). CRFS scores were regressed simultaneously on the entire set of antecedents, which accounted for $27 \%$ of the variance. Only personal dedication to fostering, time available to foster, and parental acceptance had independent effects.

Outcomes. Bivariate correlations were used to examine the effect of CRFS scores on hypothesized outcomes (see Table 7). All of these correlations were in the hypothesized direction, and all but one (Potential to Manage Worker/Agency Challenges) was statistically significant. The statistically significant correlations ranged from .23 to .39.

Multivariate linear regression was used to examine the effect of CRFS scores on the hypothesized multidimensional outcomes (see Table 9). These outcomes were regressed simultaneously on CRFS scores, which accounted for $28 \%$ of the variance. Except for Potential to Manage Worker/Agency Challenges, all of the partial correlations were statistically significant, and they ranged from .22 to .42 .

Binary logistic regression was used to test hypotheses concerning intention to continue fostering because these dependent variables are binary (Hosmer \& Lemeshow, 2000). Effect size was 
quantified by the odds ratio (OR) associated with a one standard deviation increase in CRFS scores, calculated as $\mathrm{OR}=\mathrm{e}^{(\mathrm{B} \times \mathrm{SD})}$.

For every one standard deviation increase in CRFS scores, mothers were 1.60 times more likely to plan to continue fostering for the next 6 months (see Table 10).

TABLE 9. Hypothesized Outcomes Regressed on Cultural Receptivity in Fostering Scale ( $\mathrm{n}=$ 286)

\begin{tabular}{|l|l|l|l|}
\hline Outcomes & B & SE B & Partial Eta \\
\hline Cultural Competence Scale (CCS) & $.35^{* *}$ & .06 & .35 \\
\hline CFAI-A: Promote Foster Child Development (CFAI-A/FCD) & $.01^{* *}$ & $<.01$ & .42 \\
\hline CFAI-A: Foster Challenging Children (CFAI-A/CC) & $.01^{* *}$ & $<.01$ & .37 \\
\hline CFAI-A: Manage Worker/Agency Challenges (CFAI-A/WAC) & $<.01$ & $<.01$ & .11 \\
\hline Receptivity to Working with Birth Families Scale (RWBFS) & $.23^{* *}$ & .04 & .35 \\
\hline WFS: Behavioral or Emotional Problems (WFS-BEP) & $.32^{* *}$ & .07 & .26 \\
\hline WFS: Special Needs (WFS-SN) & $.27^{* *}$ & .07 & .22 \\
\hline WFS: DRRCS (WFS-DRRCS) & $.37^{* *}$ & .08 & .28 \\
\hline
\end{tabular}

NOTE: CFAI-A = Casey Foster Applicant Inventory-Applicant; WFS = Willingness to Foster Scale. $\mathrm{R} 2=.28, \mathrm{~F}(8,277)=13.22, \mathrm{p}<.001 .{ }^{* *} \mathrm{p}<.01$.

TABLE 10. Intention to Continue Fostering Regressed on Cultural Receptivity in Fostering Scale (CRFS)

\begin{tabular}{|l|l|l|l|}
\hline Variables & $\mathrm{B}$ & SE B & OR \\
\hline 6-Months & & $\mathrm{n}=304$ & \\
\hline CRFS & $.031^{*}$ & .015 & 1.60 \\
\hline 1-Year & & $\mathrm{n}=303$ & \\
\hline CRFS & .024 & .014 & 1.44 \\
\hline 3-Years & & $\mathrm{n}=304$ & \\
\hline CRFS & .008 & .012 & 1.13 \\
\hline
\end{tabular}

$* \mathrm{p}<.05$

TABLE 11. Availability and Utilization Regressed on Cultural Receptivity in Fostering Scale (CRFS)

\begin{tabular}{|l|l|l|l|}
\hline Variable & $\mathrm{B}$ & $\mathrm{SE}$ B & $\Delta \%$ \\
\hline Years fostered & & $\mathrm{n}=304$ & \\
\hline CRFS & -.002 & .004 & -3.00 \\
\hline Licensed capacity & & $\mathrm{n}=303$ & \\
\hline CRFS & .001 & .002 & 1.54 \\
\hline Children fostered & & $\mathrm{n}=304$ & \\
\hline Years fostered & $.127^{* *}$ & .009 & 149.97 \\
\hline CRFS & -.002 & .004 & -3.00 \\
\hline Children removed & & $\mathrm{n}=295$ & \\
\hline
\end{tabular}




\begin{tabular}{|l|l|l|l|}
\hline Years fostered & $.071^{* *}$ & .009 & 66.89 \\
\hline CRFS & -.006 & .005 & -8.75 \\
\hline Children adopted & & $\mathrm{n}=296$ & \\
\hline Children fostered & $.004^{*}$ & .002 & 31.03 \\
\hline CRFS & .004 & .006 & 6.29 \\
\hline Children in home & & $\mathrm{n}=303$ & \\
\hline Licensed capacity & $.183^{* *}$ & .019 & 36.16 \\
\hline CRFS & .001 & .003 & 1.54 \\
\hline
\end{tabular}

NOTE: Poisson regression was used in the analysis of licensed capacity and children in the home. Negative binomial regression was used in the remaining analyses. ${ }^{*} \mathrm{p}<.05 .{ }^{* *} \mathrm{p}<.01$.

There was not a statistically significant relationship between CRFS scores and intention to continue fostering for the next year or the next 3 years.

Poisson or negative binomial regression was used to test hypotheses when the dependent variable was a count (DeMaris, 2004; Long, 1997; Orme \& Buehler, 2001), and LIMDEP (Version 8) (W. H. Greene, 2002) was used for these analyses. Count variables included the number of years fostered, children licensed to foster, children fostered, foster children removed, foster children adopted, and foster children in the home. Negative binomial regression was used when overdispersion was present (years fostered, children fostered, children removed, children adopted), and Poisson regression was used when it was not (licensed capacity, children in the home). Effect size was quantified by the percentage change associated with a one standard deviation increase in the predictor variable $(\Delta \%)$, CRFS. Percentage change was calculated as $\Delta \%=100 \times\left(\mathrm{e}^{(B \times S D)}-1\right)$, and it indicates the percentage change in the dependent variable associated with a one standard deviation increase in the CRFS when controlling for other variables in the model (W. H. Greene, 2000).

Finally, in testing validity hypotheses concerning utilization, availability was controlled statistically by first entering the requisite availability variable in the regression equation and then entering the CRFS. Specifically, the number of years fostered was controlled in examining the number of children fostered because those who had fostered longer had the opportunity to foster more children. The number of children fostered was controlled in examining the number of children removed and the number of children adopted because those who fostered more children had more opportunities to request removal of foster children and to adopt foster children. Finally, licensed capacity was controlled in examining the number of foster children in the home because those with a greater capacity had the opportunity to foster more children at a given time.

There was not a statistically significant relationship between CRFS scores and the number of years fostered, children licensed to foster, children fostered, foster children removed, foster children adopted, or foster children in the home (see Table 11).

\section{LIMITATIONS}


The present study includes a demographically diverse national sample of foster mothers from public and private agencies, with considerable variation in fostering experience. However, results should be considered with regard to the fact that a nonprobability sample of licensed foster mothers was used. The age and marital status of mothers are similar to those in the only national probability sample of licensed foster parents, the National Survey of Current and Former Foster Parents (NSC\&FFP) (Cox, Orme, \& Rhodes, 2002; Rhodes, Orme,\& Buehler, 2001). However, a higher proportion of mothers in the present study are European American, and families in the present study have higher annual family incomes. Also, a higher proportion of mothers are college educated and employed outside of the home.

Foster mothers in the present study also were relatively more experienced at fostering and more committed to continue fostering than those in the NSC\&FFP. Although families in the present study were licensed to foster the same number of children, and approximately the same percentage of families was below licensed capacity, mothers in the present study had fostered longer and fostered more children. Also, a higher percentage planned to continue fostering, and a higher percentage had foster children in their homes.

Results of the present study also should be considered in view of the cross-sectional design used. Mothers who intended to quit probably were underrepresented, as were mothers who fostered a shorter time, those licensed to foster fewer children, mothers who had fostered fewer children, mothers who had requested the removal of fewer children, mothers who had adopted more children, and mothers with fewer foster children in the home (Gibbs, 2004). Foster mothers who are less open toward participating in activities that promote children's cultural development also might be underrepresented. Underrepresentation of these groups would result in a sample with less variability in CRFS scores and indicators of availability and utilization. This in turn might lead to underestimates of the strength of relationships between CRFS and these outcomes, which might be one reason why some validity hypotheses were not supported.

Another limitation of this study involves the use of a sample of current foster mothers. First, the CRFS was intended to measure prospective foster parents' cultural receptivity. However, this study utilized a sample of current foster mothers; it does not necessarily reflect the opinions of current foster fathers or foster parent applicants.

Second, a possible disadvantage to using experienced foster mothers as the reference population that should be considered in interpreting the scores of applicants is that the bar might be set too high for foster parent applicants by comparing them to approved foster parents instead of to other applicants. However, because at this time no sample was obtained of foster parent applicants on which to norm the CRFS, this is not known to be a fact. The interpretation of the CRFS scores for foster parent applicants should be performed with some caution because the normative scores do not include prospective foster mothers and foster fathers for whom the scale was developed. Although the scale was developed to assess prospective foster parents, using the CRFS to assess current foster parents would also be appropriate. 
Matching foster parents and foster children was discussed above as one of the potential uses of the CRFS. However, whether foster parents with greater cultural receptivity actually provide culturally appropriate fostering to children of different cultures is unknown. The limitations of the data collected did not allow this substantive question to be answered. Because data were not collected regarding foster children's races, it is unknown whether foster mothers who were more culturally receptive had previously fostered transculturally. In addition, questions regarding intentions to continue fostering children of different cultures, specifically, could not be examined. This is because it is unknown whether foster mothers were currently fostering children of different cultures at the time of this study. The CRFS should be tested in future studies with foster parents who have parented transculturally. Furthermore, data collection methods should include the means to gather information concerning current and past record of fostering children of different cultures.

\section{DISCUSSION AND APPLICATIONS TO RESEARCH AND PRACTICE}

Cultural receptivity is related to a number of different characteristics of overall fostering quality. For instance, foster mothers who were more culturally receptive also were more culturally competent. This was an important finding because there are no theories that specifically address cultural receptivity. Cultural competence theory was employed in order to fill gaps in the literature that links the areas of transcultural fostering and cultural competence.

Chau (1992), Dillon (1994), McRoy (1994), and Weaver (1998) are a few of the researchers who addressed changing one's attitude, behavior, knowledge, and skills (or knowledge, skills, and values), which are all efforts that are needed in order to work with people of diverse cultures. Vonk (2001) demonstrated how cultural competence was extended to transracial parenting, wherein adoptive parents need to possess certain knowledge, behaviors, and skills to appropriately parent children of different cultures than their own. Cultural receptivity is directly related to this because it examines how open foster parents are to being involved in cultural parenting strategies that involve acquiring culturally specific knowledge, behaviors, and skills. Therefore, it is important to demonstrate how openness to certain cultural parenting activities predicts cultural competence.

Within the confines of the cultural receptivity theoretical framework, culturally receptive foster parents are willing to seek training, support, and services that increase their transcultural parenting abilities. The increased ability to parent children of different cultures in a socially appropriate manner translates to their becoming more culturally competent as well as receptive to ongoing participation in culturally stimulating activities.

This cultural receptivity research has implications for social work practice, particularly in the area of foster parent training. In a national study of state child welfare agencies' training protocols, Rhodes et al. (2002) found that all foster parent training modules do not adequately address the role of culture and its effects on fostering. This is unfortunate because training that is 
specific to transcultural fostering would be an important area to consider when examining foster parents' cultural receptivity. For instance, modules that include components of culture, racial awareness, multicultural planning, and survival skills for minority children (Vonk \& Angaran, 2001) would be ideal (p. 13). Vonk and Angaran (2001) showed that cultural competence training administered to pretransracial adoptive parents positively influenced their perception of the importance for children's cultural development. Other researchers also have used training to examine aspects of cultural competence in human services workers (Mitchell, 1999; Montalvo, Lassater, \& Valdez, 1982).

Cultural training, services, and support are intended to help foster parents learn appropriate cultural fostering strategies. Decisions about how to best meet applicants' needs through these provisions should be contingent on the interpretation of CRFS scores, as well as social workers' professional judgment. In turn, foster parents will be better able to foster children of minority cultures because they will have received adequate and appropriate cultural training, services, and support, thus increasing retention.

Foster parent retention is an important aspect to investigate because social workers need to know something about foster parent applicants' intentions to continue fostering. As discussed above, there is support that greater cultural receptivity leads to foster mothers' planning to foster short term. However, cultural receptivity is not related to long-term foster mother retention (i.e., intention to foster 1 year and 3 years). A possible reason concerns the need to provide applicants information about the availability of ongoing cultural training, services, and support in order to ease their fears and increase their understanding about transcultural fostering. This might, in turn, increase their commitment to transcultural fostering.

Another possible reason could be due to the very low percentage of foster mothers who planned to discontinue fostering. The fact that the CRFS was tested on approved foster mothers and not applicants might have influenced the results as well. For instance, it could be expected that applicants' responses would differ from current foster mothers at the time of assessment.

Foster mothers' intentions might also be influenced by the need to participate in culturally appropriate parenting strategies. McPhatter (1997) and R. R. Greene and Watkins (1998) assert that cultural competence is "a developmental process that requires long-term commitment" (Vonk, 2001, p. 247). Also, Cox et al. (2002) report that foster parents who are willing to foster certain types of children (i.e., special needs) foster longer than those who are not willing. It seems that foster parents would foster longer because they are more open to fostering the various kinds of children likely to be placed in their care. Foster parents might also be committed to fostering these children because they have invested additional time and effort in learning how to support their cultural development. However, because data were not collected regarding the children's cultures, there is no way of knowing whether more foster mothers who fostered culturally different children would have intended to foster long term compared to those who did not. 
A final practice implication for cultural receptivity research involves transcultural foster parents' need for support in working with the child welfare agency, community organizations, and birth parents in order to improve the quality of foster care. Though their ability to utilize these resources increases their ability to foster children from different cultures (Cox, 2000), the findings from the cultural receptivity study did not support a relationship between cultural receptivity and dealing with worker and agency challenges.

Perhaps this could be because the CRFS items in the scale pertain more to promoting positive outcomes for children, whereas the WAC subscale's main focus is on relationships with the social worker and agency. Foster mothers might not have connected the scale's specific items in dealing with the agency and social worker to working with foster children.

This cultural receptivity research also has implications for policies, such as MEPA (1994) and IEAP (1996), as well as the Child Welfare League of America's position on transcultural placements. Currently, the policies on transcultural placements support the principle that decisions about children's permanence will not be based solely on culture. Furthermore, policies state that children's placements will not be hindered due to the inability to secure same-culture foster homes.

The results of this study could supplement transcultural placement policies by requiring that the fostering of culturally different children be contingent upon foster parents' willingness to commit to appropriate cultural fostering strategies as evaluated by such assessment instruments as the CRFS at the time of application. Furthermore, ongoing transcultural fostering and consequent transcultural adoption could be evaluated using cultural receptivity and other cultural competence assessments concerning foster parents' openness and ability to parent and work with people of diverse cultures. The outcomes should show continued growth in the areas of openness toward becoming active participants in promoting the cultural identities and growth of children of minority cultural backgrounds. This can be achieved through the use of the CRFS for continual evaluation of foster parents' development.

The following are recommended for research that will build on the findings from the current cultural receptivity study. Future research should entail a longitudinal study of both foster mother and foster father applicants, as this current cross-section study investigated only current foster mothers. These improved methods would allow the results to be generalized to both male and female foster parent applicants in the general population and lend further support regarding the predictability of CRFS scores. In regards to the predictability of this measure, the CRFS should be used cautiously. This is a new measure and construct that should also be tested in future studies with foster mothers and fathers who have parented transculturally.

Additional research might also seek to establish convergent validity between the CRFS and the Transracial Adoption Parenting Scale (Massatti et al., 2004), a measure of adoptive parents' cultural competence. These two relatively new scales appear to measure theoretically similar 
constructs; therefore, a positive, high correlation of results would provide support that they converge on the same construct.

Next, more emphasis needs to be placed on research that examines foster parents' commitment to transcultural parenting. This can be studied in the following ways. First, future research could examine whether prospective foster parents' level of cultural receptivity predicts their decision to foster children of different cultural backgrounds. Second, for those who do foster transculturally, research could examine whether cultural receptivity predicts their retention with fostering culturally different children. Third, research might address how foster parents' level of cultural receptivity is related to outcomes for children of different cultures such as cultural identity.

In conclusion, the state has an obligation to prepare foster children for successful futures. Therefore, careful assessment of foster parent applicants should be employed in order to ascertain whether they are receptive to participating in culturally stimulating parenting strategies when raising foster children of different cultural backgrounds. The CRFS is a promising assessment tool that would aid greatly in this discovery. Therefore, in light of this study's collective empirical evidence and theoretical support, the CRFS is recommended as a reliable and valid measure to be used cautiously, until further rigorous testing, in the assessment of prospective foster parents who will foster children of different cultures.

\section{APPENDIX CULTURAL RECEPTIVITY IN FOSTERING SCALE}

Foster children have different cultures. Culture tells us how groups of people are different, whether they are from a different race, ethnicity, religion, spirituality, gender, sexual orientation, social class, or other ways that influence values, beliefs, views, and behavior. Below is a list of activities involved in fostering children of different cultures. For each statement, please select the response that best explains the level of effort that you are willing to give to do the following activities.

$1=$ None $2=$ Little $3=$ Some $4=$ A lot $5=$ Whatever it takes

Scale Statements

1. Seeking help from people who share his/her culture.

2. Finding out about the skin and hair care that are best for a foster child.

3. Learning how to tell if others are unkind or unfair to a foster child because of his or her culture.

4. Finding places where a foster child can go to get his or her cultural needs met.

5. Celebrating holidays and events important to a foster child.

6. Buying toys, books, and dolls that are like a foster child's culture.

7. Showing interest in the art of a foster child's culture.

8. Learning how to lessen the effects of racism or discrimination on a child.

Response \#

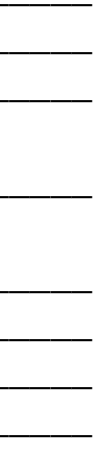

9. Sharing helpful ideas with others who have raised children of different 
cultures.

10. Trying recipes from a foster child's culture.

11. Learning how to help a foster child effectively cope with acts of prejudice and racism.

12. Appreciating clothing styles that are important to a foster child's culture.

13. Finding out about the health issues that are common in a foster child's culture.

14. Becoming more aware of how racism or discrimination affects people from different cultures.

15. Learning about how parenting practices of a foster child's culture differ from my own.

16. Appreciating the music of a foster child's culture.

17. Considering how my stereotypes about cultures affect a foster child.

18. Learning how children benefit from interacting with other children from different cultures.

19. Learning how I can help a foster child maintain his/her culture.

20. Learning about how a foster child may have different views about the community than I do.

21. Finding ways a foster child can fit into my family without changing things about his/her culture.

22. Examining how my beliefs and values affect aspects of a foster child's culture.

23. Learning to teach a foster child about racism and discrimination.

24. Learning about language expressions of a foster child's culture.

25. Taking a foster child to cultural places and events.

\section{REFERENCES}

American Educational Research Association, American Psychological Association, \& National Council on Measurement in Education. (1999). Standards for educational and psychological testing (2nd ed.). Washington, DC: American Educational Research Association.

Barnett, M. A., \& Sinisi, C. S. (2000). Barnett Liking of Children Scale [BLOCS]. In K. Corcoran \& J. Fischer (Eds.), Measures for clinical practice: A sourcebook (3rd ed., Vol. 2, pp. 101-103). New York: Free Press.

Buehler, C., Orme, J. G., Cuddeback, G. S., Le Prohn, N., Cox, M. E. (2003). Casey Foster Applicant Inventory (CFAI): User's manual. Knoxville: University of Tennessee, Children's Mental Health Services Research Center.

Chau, K. L. (1992). Educating for effective group work practice in multicultural environments of the 1990's. Journal of Multicultural Social Work, 1(4), 1-15. 
Child Welfare League of America. (2000). Standards of excellence for adoption services. Washington, DC: Child Welfare League of America.

Coakley, T. M. (2004). Assessing cultural receptivity in fostering: Scale development and validation. Dissertation Abstracts International, 65(07), 2764. (UMI No. 3141803)

Cohen, J., Cohen, P., West, S. G., \& Aiken, L. S. (2003). Applied multiple regression/correlation analysis for the behavioral sciences (3rd ed). Mawah, NJ: Lawrence Erlbaum.

Cox, M. E. (2000). Characteristics of foster family applicants willing to accept hard to place foster children. Unpublished doctoral dissertation, University of Tennessee, Knoxville.

Cox, M. E., Orme, J. G., \& Rhodes, K. W. (2002). Willingness to foster special needs children and family utilization. Children and Youth Services Review, 24, 293-317.

Curtis, C. M. (1996). The adoption of African-American children by whites: A renewed conflict. Families in Society, 77, 156-164.

Deberry, K. M., Scarr, S., \& Weinberg, R. A. (1996). Family racial socialization and ecological competence: Longitudinal assessments of African-American transracial adoptees. Child Development, 67, 2375-2399.

DeMaris, A. (2004). Regression with social data: Modeling continuous and limited response variables. Hoboken, NJ: John Wiley.

Dillon, D. (1994). Understanding and assessment of intragroup dynamics in family foster care: African-American families. Child Welfare, 73, 129-137.

Fabrigar, L. R., Wegener, D. T., MacCallum, R. C., \& Strahan, E. J. (1999). Evaluating the use of exploratory factor analysis in psychological research. Psychological Methods, 4, 272-299.

Feigelman, W., \& Silverman, A. R. (1983). Chosen children: New patterns of adoptive relationships. New York: Praeger.

Gibbs, D. A. (2004). Understanding foster parenting: Using administrative data to explore retention (Report prepared by RTI International for U.S. Department of Health and Human Services; Office of Assistant Secretary for Planning and Evaluation). Washington, DC: U.S. Department of Health and Human Services.

Greene, R. R., \& Watkins, M. (Eds.). (1998). Serving diverse constituencies: Applying the ecological perspectives. New York: Aldine de Gruyter.

Greene,W. H. (2000). Econometric analysis (4th ed.). Upper Saddle River, NJ: Prentice Hall.

Greene, W. H. (2002). LIMDEP. Plainview, NY: Econometric Software. 
Grow, L., \& Shapiro, D. (1974). Black children, White parents. New York: Child Welfare League of America.

Hosmer, D. W., \& Lemeshow, S. (2000). Applied logistic regression (2nd ed.). New York: John Wiley.

Illinois Department of Children and Family Services (1993). Parent Resources for Information, Development, and Education [PRIDE]. Washington, DC: Child Welfare League of America.

Interethnic Adoption Provision of 1996, Pub. L. No. 104-188, §1808, 110 Stat. 1903 (1996).

Le Prohn, N. S. (1993). Relative foster parents: Role perceptions, motivation and agency satisfaction. Unpublished doctoral dissertation, University of Washington.

Le Prohn, N. S. (1994). The role of the kinship foster parent: A comparison of the role conceptions of relative and non-relative foster parents. Children and Youth Services Review, 16, 65-84.

Loehlin, J. C. (1998). Latent variable models: An introduction to factor, path, and structural analysis (3rd ed.) Mahwah, NJ: Lawrence Erlbaum.

Long, J. S. (1997). Regression models for categorical and limited dependent variables. Thousand Oaks, CA: Sage.

Massatti, R. R.,Vonk, M. E., \& Gregoire, T. K. (2004). Reliability and validity of the Transracial Adoption Parenting Scale. Research on Social Work Practice, 14, 43-50.

McPhatter, A. R. (1997). Cultural competence in child welfare: What is it? How do we achieve it? What happens without it? Child Welfare, 76, 255-278.

McRoy, R. G. (1994). Attachment and racial identity issues: Implications for child placement decision making. Journal of Multicultural Social Work, 3(3), 59-75.

McRoy, R. G., \& Zurcher, L. A. (1983). Transracial and inracial adoptees. Springfield, IL: Charles C Thomas.

Mitchell, E. R. (1999). Assessment and development of cultural competence. Ann Arbor, MI: UMI Dissertation Services. (UMI No. 9965529)

Montalvo, F. F., Lassater, T. T., \& Valdez, N. G. (1982). Training child welfare workers for cultural awareness: The cultural simulator technique. Child Welfare, 61, 341-352.

Multiethnic Placement Act of 1994, Pub. L. No. 103-382, §551, 108 Stat. 4056 (1994).

Orme, J. G., \& Buehler, C. (2001). Foster family characteristics and behavioral and emotional problems of foster children: A narrative review. Family Relations, 50, 3-15. 
Orme, J.G., Cherry, D.J., \& Rhodes, K.W. (in press). The help with fostering inventory, Children and Youth Services Review.

Orme, J. G., Cox, M. E., Rhodes, K. W., Coakley, T. M., Cuddeback, G. S., \& Buehler, C. (2003). Casey Home Assessment Protocol: Technical manual. Knoxville: University of Tennessee, Children's Mental Health Services Research Center.

Orme, J. G., Cuddeback, G. S., Buehler, C., Cox, M. E., \& Le Prohn, N. (2003). Casey Foster Applicant Inventory (CFAI) technical manual. Knoxville: University of Tennessee, Children's Mental Health Services Research Center.

Pasztor, E. M., \& Child Welfare Institute \& Center for Foster and Residential Care. (1990). Model Approach to Partnerships in Parenting [MAPP Program Guidebook]. Atlanta, GA: Child Welfare Institute.

Pecora, P. J., Le Prohn, N. S., \& Nasuti, J. J. (1999). Role perceptions of kinship and other foster parents in family foster care. In R. Hegar \& M. Scannapieco (Eds.), Kinship foster care: Policy, practice, and research (pp. 155-178). New York: Oxford University Press.

Rhodes, K. W., Coakley, T. M., \& Orme, J. G. (2002). [Foster parent training and assessments]. Unpublished raw data.

Rhodes, K. W., Cox, M. E., Coakley, T. M., \& Orme, J. G. (under review). Motivation to foster: A national study. Journal of Sociology and Social Welfare.

Rhodes, K. W., Orme, J. G., \& Buehler, C. (2001). A comparison of family foster parents who quit, consider quitting, and plan to continue fostering. Social Service Review, 75, 84-114.

Rhodes, K. W., Orme, J. G., Cox, M. E., Coakley, T. M., Buehler, C., \& Cuddeback, G. (2003). Casey home assessment protocol: User's guide. Knoxville: University of Tennessee, Children's Mental Health Services Research Center.

Rhodes, K. W., Orme, J. G., \& McSurdy, M. (2003). Foster parents’ role performance responsibilities: Perceptions of foster mothers, fathers, and workers. Children and Youth Services Review, 25, 225.

Schaefer, E. S. (1965). Children’s reports of parental behavior: An inventory. Child Development, 36, 413-426.

Schludermann, E., \& Schludermann, S. (1970). Replicability of factors in the Children's Report of Parental Behavior Inventory (CRPBI). Journal of Psychology, 96, 15-23.

Shadish,W. R., Cook, T. D., \& Campbell, D. T. (2002). Experimental and quasi-experimental designs for generalized causal inference. Boston, MA: Houghton Mifflin. 
Sharma, A. R., McGue, M. K., \& Benson, P. L. (1996). The emotional and behavioral adjustment of United States adopted adolescents: part 1. An overview. Children \& Youth Services Review, 18, 83-100.

Shireman, J. F., \& Johnson, P. R. (1986). A longitudinal study of Black adoptions: Single parent, transracial, and traditional. Social Work, 31, 172-176.

Silverman, A. R. (1993). Outcomes of transracial adoption. The Future of Children, 3(1), 104118.

Simon, R. J., \& Alstein, H. (1996). The case for transracial adoption. Children and Youth Services Review, 18(1/2), 5-22.

Thoburn, J., Norford, L., \& Rashid, S. P. (2000). Permanent family placement for children of minority ethnic origin. London and Philadelphia: Jessica Kingsley.

U. S. Department of Health and Human Services, Administration for Children and Families, Administration on Children, Youth and Families, Children's Bureau. (2000). Adoption and Foster Care Analysis and Reporting System (AFCARS) (FC2000v2) [Data file]. Washington, DC: Author.

U. S. Department of Health and Human Services, Administration for Children and Families, Administration on Children, Youth and Families, Children's Bureau. (2005). Adoption and Foster Care Analysis and Reporting System (AFCARS). Retrieved from http://www.acf.hhs.gov/programs/cb/stats_research/afcars/tar/report10.htm

Vonk, M. E. (2001). Cultural competence for transracial adoptive parents. Social Work, 46, 246255.

Vonk, M. E., \& Angaran, R. (2001). A pilot study of training adoptive parents for cultural competence. Adoption Quarterly, 4(4), 5-18.

Vroegh, K. S. (1997). Transracial adoptees: Developmental status after 17 years. American Journal of Orthopsychiatry, 67, 568-575.

Weaver, H. N. (1998). Indigenous people in a multicultural society: Unique issues for human services. Social Work, 44, 217-225.

Zuniga, M. E. (1991). Transracial adoption: Educating the parents. Journal of Multicultural Social Work, 1(2), 17-31.

Authors' Note: Casey Family Programs supported this work. This research was conducted for the fulfillment of the first author's doctoral dissertation at the University of Tennessee and was presented at The Ohio State University Seventeenth National Symposium on Doctoral Research in Social Work on April 16, 2005. The authors thank Casey Family Programs, Niki LeProhn, and 
the University of Tennessee Foster Family Research Team members, Cheryl Buehler, Mary Ellen Cox, Gary Cuddeback, Kathryn Rhodes, and Donna Cherry for their support and contributions to the overall Casey Home Assessment Protocol study from which the data for this study were produced. We also thank Terri Combs-Orme for her helpful suggestions during the development of this article. Correspondence may be addressed to Tanya M. Coakley, University of North Carolina at Greensboro, Department of Social Work, P.O. Box 26170, Greensboro, NC 27402-6170, or via e-mail using tcoakley@uncg.edu. 